УДК 78.03/782.1

\title{
Ван Пен
}

\section{СИНТЕТИЧЕСКАЯ ПРИРОДА ОПЕРНОГО ОБРАЗА В ОПЕРАХ В. МОЦАРТА}

\begin{abstract}
Статья обращена к задаче адекватного сиенического музыкального воспроизведения образов опер В. Моцарта в условиях современного режиссерского театра. Предлагаются различные способы современного прочтения - представления оперных замыслов Моцарта, выделяются главные приемы создания образов ведущих персонажей опер. Сопоставляются общая драматическая и специфическая вокально-интонационная стороны создания оперного характера.
\end{abstract}

Ключевые слова: оперный образ, оперный характер, оперная драматургия, оперный замысел, персонификация.

К известным словам Г. В. Чичерина о том, что Моцарт более композитор XIX столетия, чем XVIII и более XX, чем XIX [8], сегодня можно добавить: и более XXI, чем XX. Данные слова касаются, прежде всего, оперных произведений В.-А. Моцарта, являющихся классической основой современного оперного театра. Понятие о классическом в данном контексте приобретает три значения. Во-первых, это указание на историческое время музыки Моцарта, его оперных замыслов, обусловленных театральной классицистской эстетикой и музыкальным языком, сформированным в творчестве так называемых «венских классиков», среди которых был и сам Моцарт. Вовторых, понятие классический в связи жанровой природой оперного театра становится характеристикой тех оперных творений, без которых не может обойтись оперный репертуар, которые являются образцовыми и обязательными в подтверждении профессионального уровня музыкально-театральной деятельности. В-третьих, классическими оперы Моцарта сегодня могут быть названы еще и потому, что они в значительной мере способствуют развитию «режиссерского театра», выступают постоянным объектом постановочной интерпретации, следовательно - являют классические примеры современной реконструкции сценического содержания оперного произведения.

Этому способствует сложность и многозначность образов персонажей, заполняющих семантическое пространство моцартовских опер, то есть концепционная многослойность и даже таинственность моцартовских оперных замыслов.

(C) Ван Пен, 2014 
Из всех опер чаще всего к творческому эксперименту подталкивают две из них - «Дон Жуан» и «Волшебная флейта», поскольку они являются самыми новаторскими и необычными музыкально-сценическими сочинениями В. Моцарта. На это обращают внимание Л. Кириллина, В. Широкова, Е. Чигарева (которая является автором фундаментальной работы «Оперы Моцарта в контексте культуры его времени. Художественная индивидуальность. Семантика» [7]), М. Изворская-Елизарьева, находящая в «Волшебной флейте» «космогоническую мифологию» [3].

О новом значении и неисчерпаемом образно-смысловом богатстве данных опер свидетельствуют новые постановки «Дон Жуана». В частности, немецкий кинорежиссер Михаель Ханеке (известный как режиссер «Пианистки») поставил «Дон Жуана» на сцене Парижской национальной оперы (27.01.2006 г.), а открытие 60-го сезона Лирик-оперы 2014-2015 годов в Чикаго было совершено благодаря новой постановке оперы Моцарта «Дон Жуан» Робертом Фоллсом. Но сколько бы ни возникало традиционных, радикально новаторских или умеренно обновленных постановочных версий «веселой драмы» Моцарта, все они следуют к одной цели: раскрыть подлинное психологическое содержание драматургии оперы, выявить все сложности и тонкие детали тех психологических дуэлей, которые происходят между персонажами оперы на всем ее протяжении. Исходя из этого, главной задачей нашей статьи становится выявление той синтетической сложности образа главного героя оперы, Дон Жуана, на основе которой возникает полифоническая идейно-образная конструкция оперы в целом.

Основной «психологический контрапункт» в опере «Дон Жуан» Моцарта возникает между образами Жуана и Командора, и возникает он музыкально-тематическим путем. Весь музыкально-тематический материал оперы поляризуется и представляет некую образную дуэль жизни, воплощенной в главном герое, и смерти, провозвестником которой выступает Командор. Причем начало этой дуэли кладет интродукция к опере, а конец совпадает с финалом второго действия, то есть с завершением всей оперы и ее генеральной кульминацией. Уместно заметить, что, унаследовав некоторые принципы буффонной оперы, Моцарт часто строит финальные сцены именно как ансамблевые с постепенным подключением все большего количества героев, пока на сцене не оказываются все основные персонажи, то есть строит финалы по принципу ситуативного и смыслового кре- 
щендо. Однако ансамблевый характер образа Дон Жуана, этого главного «коммуникатора» оперы, не исчерпывается его противостоянием Командору - как страху смерти, угасанию жизненной энергии и чувства любви. Свои собственные, особые отношения Дон Жуан устанавливает со всеми действующими лицами; не только с «трио мстителей», которое представляется ослабленным отсветом мертвенной тайны Командора, но и с лирико-патетической Эльвирой и простодушно-пасторальными Церлиной и Мазетто, наконец, с профанно-грубоватым Лепорелло.

С одной стороны, Дон Жуан с каждым из них «говорит» на их языке, как на том языке, который им понятен. Его партия отличается стилистической подвижностью и изменчивостью, как изменчив, восприимчив ко всему многообразию жизни он сам. С другой стороны, интонации Дон Жуана, показательные для него тонально-ладовые признаки внедряются в партии иных персонажей, подчиняют себе их характеры, выявляя особую власть Жуана над людьми (не только над женщинами), его талант «творчества жизни». Центром собирания музыкального Эго Жуана является его Ария с шампанским (си бемоль мажор), значение которой в полной мере раскрывается монотематическим путем, то есть благодаря участию ее выразительных элементов в ансамблевых сценах, в обращении к остальным персонажам оперы.

Финал второго акта - кульминация основной образной и музыкальной линии оперы. В нем сходятся основные нити предшествующего тематического развития. Моцарт использует и праздничный ре мажор, напоминающий сонатное аллегро увертюры, и развернутый раздел в си бемоль мажоре, и динамизированное воспроизведение материала вступительной части увертюры (темы рока) и сцены поединка Командора с Дон Жуаном. Данный финал подтверждает смысл ансамблевого взаимодействия полярных образов оперы, открывая их внутреннюю связь: интонации и гармонии Командора заложены в музыкальном языке Дон Жуана с их первой встречи; данные образы создают «ансамбль высшего порядка», воссоздавая таким образом антиномию жизни - смерти, указывая на гибель Жуана как на миг его торжества над смертью. Высшее ощушение полноты жизни при встрече со смертью - вполне пушкинская идея, заставившая российского поэта строить свои «маленькие трагедии» по-моцартиански...

В ходе оперы Дон Жуана и Командора характеризует контрастный музыкальный материал: мажор - минор, преобладание автентических оборотов, диатоники, трезвучных и квартовых оборотов в 
партии Жуана - плагальности, альтераций, отклонений, хроматических ходов, фригийского лада, уменьшенных интервалов в партии Командора. Однако в Арии с шампанским в средней части звучит хроматизированная фраза, в гармонии появляется двойная доминанта и мажор сменяется минором, то есть присутствуют стилистические элементы образа Командора. И наоборот. Вступление в увертюре начинается с кварты и полуавтентического оборота. По справедливому наблюдению Е. Чигаревой, «так же как мажорный тетрахорд мотива арии «с шампанским» представляет собой зеркальное отражение фригийского тетрахорда увертюры, лейтинтервал Дон-Жуана (автентическая кварта) является своеобразным обращением темы-эпиграфа (восходящее движение вместо нисходящего и устойчивое окончание вместо неустойчивого). Такое «сходство по контрасту» лишний раз доказывает, что конфликтные сферы обладают взаимообратимостью, это два облика одной идеи» [7, с. 90]. Добавим к этому, что ре мажор как одна из тональных «красок» Дон Жуана является одноименной к ре минору - лейттональности Командора и «мстителей».

Последняя сцена с Командором - не только трагическая развязка, логическое завершение основного психологического противостояния, но и кульминация образа Дон Жуана. Чигарева называет ее поединком, в котором «физическое уничтожение героя отнюдь не означает его поражения» [7, с. 113].

Ответ Дон Жуана Командору со словами «Меня еще не знали как труса никогда» звучит как реминисценция минорного срединного фрагмента арии с шампанским. Такое завершение музыкальной судьбы Дон Жуана в опере Моцарта позволило Б. Чичерину написать следующие строки: «Моцартовский Дон-Жуан - сверхчеловек, бросающий вызов судьбе, во всей опере от начала до конца вырываются наружу и врываются в действие мрачные и таинственные силы судьбы, с которой герой борется, особенно <..> в конце второго финала - сверчеловеческим «Нет! Нет! Нет!» [8, с. 113].

Следовательно, комплексами музыкально-тематических образований, превращающимися в персонифицированные «темы высшего порядка», создается глубокий психологической подтекст этой «веселой трагедии», доказывается смысловая значимость образа Дон Жуана, осуществляется его художественно-эстетическое оправдание и «очищение».

Но, тем не менее, в некоторых режиссерских версиях история Дон Жуана остается историей «о распутном авантюристе, который 
неустанно преследует женщин, при этом разрушая жизнь каждого, с кем ему приходится столкнуться, в том числе и свою собственную», а потому представляет собой очень сложное произведение, как для исполнителей главных партий, так и для режиссера-постановщика.

Р. Фоллс переносит действие оперы Моцарта в Испанию 20-х гг. $\mathrm{XX}$ ст., стремясь оправдать сценический дизайн Уолта Спенглера, в который включена светорежиссура в виде неоновых знаков и фонарей, что не мешает использовать и большие статуи Мадонны и Командора и сохранять идею расплаты за греховные деяния как попадание в ад. Образ главного героя явно негативизирован сценической трактовкой; это - богатый, употребляющий кокаин плейбой, заставляющий страдать всех окружающих его людей, начиная с собственного слуги. «Этот Дон может выглядеть очаровательным в глазах женщин, но еще он является отвратительным, эгоистичным и манипулирующим людьми человеком. Возможно, он случайно выстрелил в Командора, но в следующий миг он предстает перед нами как жестокий сексуальный маньяк, как, например, в сцене банкета со связанной, окровавленной девушкой, которая словно брошенная игрушка сидит в углу сцены. Цель такой яркой демонстрации неприятных моментов - придать опере глубокий моральный посыл, который редко можно встретить в других современных постановках «Дон Жуана» в наше время. Этот Дон не просто самодовольный любовник, он коварный преступник, который в полной мере заслужил свое наказание» [1]. И, тем не менее, музыка Моцарта в исполнении высокопрофессиональных певцов служит оправданию - если не Дон Жуана, то тех чувств, которые он способен вызывать и к которым в какой-то мере причастен, то есть пассионарности ярких человеческих судеб. Знаком такой судьбы становится образ Донны Эльвиры, появляющейся на сцене (в исполнении Анны Марии Мартинес) в «облегающих бордовых штанах и в очках для езды на мотоцикле» и демонстрирующей «постоянно меняющееся состояние ее героини - от безумной любви к Дон Жуану до безумной ненависти к нему» [1].

Андриана Чучман в роли Церлины, Майкал Сумуэль в партии ее жениха Мазетто, Антонио Поли - исполнитель роли Дона Оттавио образовали равноценный и художественно действенный ансамбль солистов как группу антагонистов, способных оказать проиводействие Дон Жуану. Но тем самым они образ Дон Жуана поднимают до уровня протагониста главной музыкальной идеи оперы, которая 
в контексте данной постановки может быть представлена следующим образом: как бы ни были сильны человеческие усилия вызвать и удержать любовь, любое другое страстное чувство, окончательный приговор выносит смерть. Данный семантический аспект чикагской постановки позволяет ей сохранять связь с трагическим характером оперного творения Моцарта. Вместе с тем представление Дон Жуана как негативного центра взаимодействия позитивных по своей основной нравственной сути персонажей не вполне соответствует лирической стороне образа Жуана, явно приоткрывающейся в музыке Моцарта. О данной стороне, как наиболее важной для певца-исполнителя партии Жуана, рассуждает солист Одесского национального академического театра оперы и балета Василий Добровольский, который трижды исполнял партию Дон Жуана на различных оперных сценах, работал с тремя разными режиссерами, тремя дирижерами и тремя составами исполнителей [2].

Так, в Одесском оперном театре спектакль поставил народный артист России режиссер Юрий Александров, а дирижером-постановщиком явился народный артист Республики Молдова, главный дирижер Одесского оперного театра Александру Самоилэ. По словам В. Добровольского, после работы с А. Самоилэ любые сложности в последующих спектаклях исчезают, так как уже заложены основы стиля, нюансов, самой формы произведения; что касается постановщика, то певец отмечает, что постановка в стиле модерн, «в переплетении» с музыкой Моцарта становится неординарным и впечатляющим художественным событием, привлекательным не только для исполнителей, но и, прежде всего, для зрителей-слушателей [2]. Новая постановка оперы Моцарта в Одесском театре мотивировалась именно тем, что опера является во многих отношениях визуальным жанром, зрелищем, и зрителя нужно увлечь активным сценическим движением, потому от певцов требуется умение легко менять позы, перемещаться по сцене, петь в различных положениях и т. д., то есть становиться динамическими участниками динамического сценического события.

«Дон Жуан» в режиссерской версии Паоло Базизио, поставленный в Государственном академическом театре оперы и балета имени Абая в Алма-Ате, Республика Казахстан, в 2013 году, оказался ярким интерпретативным контрастом, поскольку спектакль был выдержан в строгом классическом стиле (от костюмов и декораций до трактовки образов и поведения героев), заставлял переноситься в эпоху Мо- 
царта, отличался амбивалентным подходом к образу главного героя, скорее свидетельствовал о возможности его ренессансной трактовки.

Третья постановка, которая наиболее позволила В. Добровольскому оценить музыкальную синтетичность образа Дон Жуана, состоялась в оперном театре города Крайова в Румынии, была осуществлена режиссёром Пламеном Карталовым, возглавляющим Государственный театр оперы в Софии, и дирижером-постановщиком Георгием Станчу [2]. Идея этого спектакля вырастала из анализа музыки Моцарта, «разбора» оперного текста «до мельчайших деталей», когда «даже самый маленький мотив композитора был осмыслен и понят до самого конца, и эти нюансы режиссер подчеркнул с помощью введения балета. В одесской постановке он тоже присутствовал, что само по себе нестандартно - когда оперный певец работает с балетом. Но для маэстро Карталова балет заполняет определенные смысловые пробелы и усиливает то, что есть. Спектакль благодаря такому подходу насыщается, появляется множество задач, чему я был только рад - это помогло мне также пересмотреть отношение Дон Жуана к другим героями и почувствовать более крепкую сюжетно-психологическую связь с ними». Отмечая способность дирижера-постановщика точно следовать стилю Моцарта, руководствоваться звуковедением, интонационной грамотностью, а не напором, силой голоса, В. Добровольский подчеркивает, что герой Дон Жуана - это сам Моцарт, а опера является «совершенно потрясающим музыкальным полотном, которое не нуждается в подтверждении своего величия и уникальности» [2].

Опыт трех режиссерских реконструкций оперы Моцарта позволяет убедиться в правомерности интерпретации образа Дон Жуана как противоречивого, даже парадоксального, но позитивного уже потому, что он относится к области «вечных образов», следовательно, связан с той ценностной сферой культуры, которая постоянно важна для становления человека. По словам В. Добровольского, «у каждой эпохи, у каждого времени и поколения есть свой Дон Жуан. Это является некой закономерностью. Когда-то давно появился не просто герой-любовник, а явление, которое называется «Дон Жуан», и оно вечное <...> Лично на мой взгляд, этого героя отличают следующие черты: он не может быть грубым, он является действительно знатоком женщин, способным без труда расположить к себе любую даму, он чертовски обаятелен и способен дать каждой именно то, что она от него ждет. Это основное для меня в работе с этой партией, ведь, 
как показал мой опыт, каждый раз я нахожу что-то упущенное ранее или делаю какие-либо новые открытия, стараясь совершенствовать мою интерпретацию от спектакля к спектаклю. Это все-таки многогранный герой, его нельзя трактовать однозначно, и мы не можем его обрисовать в один-единственный «оттенок» [2].

Музыкант приходит к выводу, что трактовка образа Дон Жуана сегодня полностью зависит от режиссера и его интерпретации идеи оперного произведения Моцарта, причем речь идет об идее, которая выходит за пределы одного образа, даже более того - которая обусловила, вызвала к сценической музыкальной жизни данный образ. «Кто-то способен выставить его жертвой всех обстоятельств, терзающимся сомнениями и ищущим чего-то идеального; кто-то показывает его героем-любовником, мастером обольщения женщин, в совершенстве овладевшим пониманием женской психологии; а для кого-то он полностью отрицательный герой, коварный соблазнитель, авантюрист, обманщик и злодей. И каждый из образов имеет право на сушествование, потому что у каждого режиссера - свое мировоззрение» [2]. Однако важнее всего обратить внимание на те параметры образа Дон Жуана, которые указывают на его связь с позитивной музыкально-эстетической идеей и объясняют тот факт, что опера Моцарта послужила образцом для трактовки сюжета Дон Жуана как трагедийно-поэтического в творчестве А. Пушкина, а именно:

- воплощение в образе Жуана поэтики игры в ее крайне напряженной экзистенциальной разновидности, как игры со смертью;

- стремление Жуана к «вечно женственному» как к спасительному онтологическому началу, которое единственно может оправдать усилия человеческой жизни и наделить их смыслом; данный параметр образа роднит его с образом Фауста из одноименной трагедии И. Гете;

- не менее ярко выраженное стремление Жуана к красоте, в том числе к красоте творчества, $к$ музыкальности человеческого действия и отношения как к его чувственному наполнению и звучанию, способному породить ответное чувство.

\section{СПИСОК ЛИТЕРАТУРЫ}

1. Денисова Д. Великолепный Моцарт [Электронный ресурс] / Д. Денисова. - Режим доступа : http://www.operanews.ru/14102003.html.

2. Добровольский В. О Дон Жуанах... [Электронный ресурс] / Василий Добровольский. - Режим доступа : www.talenthouse.md 
3. Изворская-Елизарьева М. Миф. Музыка. Моцарт: «олшебная флейта» - космогоническая мифология. - Мн.: КЦ «Рай», 1998. - 243 с.

4. Кириллина Л. Бог, царь, герой и оперная революция: к проблеме «Идоменея» / Л. Кириллина // Советская музыка. - 1991. - № 12. - С. 30-34.

5. Левик Б. История зарубежной музыки: учеб. для консерваторий / Б. В. Левик. - М.: Музыка, 1980. - Вып. 2: Вторая половина XVIII века. $277 \mathrm{c}$.

6. Маркези Г. В. Моцарт // Опера / Г. Маркези. - М., 1990. - С. 245-266.

7. Чигарева О. Оперы Моцарта в контексте культуры его времени. Художественная индивидуальность. Семантика / Е. Чигарева. - М.: Едиториал, 2000. $-280 \mathrm{c}$.

8. Чичерин Г. Моцарт. Исследовательский этюд / Б. Чичерин. - [Изд. 4-е]. - Л.: Музыка, 1979. - 285 с.

9. Широкова В. «Янычарский» стиль. Культура и варварство / В. Широкова // Советская музыка. - 1991. - № 12. - С. 38-41.

10. Эйнштейн А. Моцарт. Личность. Творчество / А. Эйештейн; [Пер. с нем]. - М.: Музыка, 1977. - 484 с.

Ван Пен. Синтетична природа оперного образу в операх В. Моцарта. Стаття звернена до завдання адекватного сценічного музичного відтворення образів опер В. Моцарта в умовах сучасного режисерського театру. Пропонуються різні способи сучасного прочитання - представлення оперних задумів Моцарта, виділяються головні прийоми створення образів провідних персонажів опер. Порівнюються загальна драматургічна та специфічна вокально-інтонаційна сторони створення оперного характеру.

Ключові слова: оперний образ, оперний характер, оперна драматургія, оперный задум, персоніфікація.

Van Pen. Synthetic nature of opera character is in operas of $V$. Mozart. The article faces to the task of an adequate stage musical reproducing of characters in operas of V. Mozart in the context of modern stage-director theatre. The different ways of the modern reading are offered and presentations of opera intentions of Mozart, the main receptions of creation of characters of leading personages of operas are distinguished. The general dramatic and specific vocally-intonation parties of creation of opera character are compared.

Key words: opera image, opera character, opera dramaturgy, opera intention, personification.

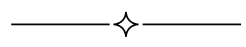

